\title{
Left atrial appendage occlusion for stroke prevention - state of the art as provided in an updated EHRA/EAPCI consensus statement and future perspectives
}

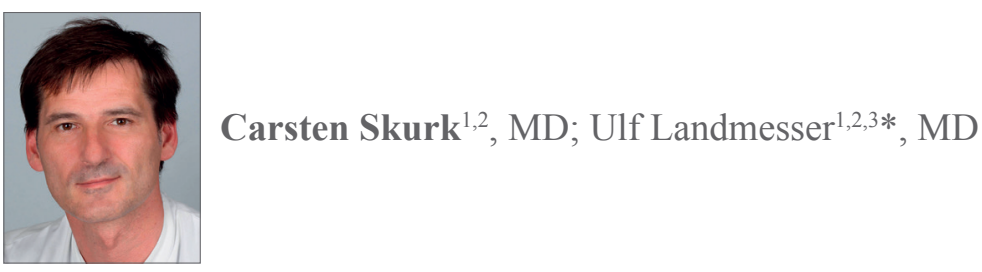

1. Department of Cardiology, Charite University Medicine Berlin, Berlin, Germany; 2, German Center of Cardiovascular Research (DZHK), Partner Site Berlin, Berlin, Germany; 3. Berlin Institute of Health, Berlin, Germany

Improving stroke prevention in patients with atrial fibrillation (AF) is of paramount clinical importance ${ }^{1}$. Although oral anticoagulation (OAC) currently remains the mainstay of stroke preventive therapy in AF, there is a significant group of patients who cannot tolerate long-term anticoagulation treatment, largely due to an increased bleeding risk. For these patients in particular, left atrial appendage occlusion (LAAO) is being developed further as an alternative mode of stroke/embolism prevention.

Since 2001, the year in which Horst Sievert, assisted by Michael Lesh, performed the first catheter-based LAAO using the percutaneous left atrial appendage transcatheter occlusion (PLAATO; ev3 Endovascular, Plymouth, MN, USA) device, and 2002 when Bernhard Meier used an AmplatzerTM device (St. Jude Medical, St. Paul, MN, USA) for the first time, significant progress in LAAO devices and implantation techniques has been achieved. In addition, it has become increasingly important to provide educational and scientific support to ensure optimal LAAO. The state of the art in this field is very nicely provided in the 2019 EHRA/ EAPCI consensus statement update. This document highlights the importance of operator training and centre readiness for LAAO programmes, describes in detail recommended implantation and management approaches for these patients, and emphasises the important role of different cardiovascular imaging modalities in pre-, peri- and post-interventional management ${ }^{2}$.

\section{Article, see page 1133}

Non-vitamin K antagonists (NOACs) have now been introduced into clinical practice ${ }^{3-5}$, providing an improved stroke prevention approach in AF patients. However, in large-scale randomised phase III clinical studies, adherence rates for NOACs after 24 months have been shown to be around $67-79 \%$, i.e., $>20 \%$ may not tolerate this therapy long term under clinical trial conditions ${ }^{3-5}$. The main reasons for discontinuation included major bleeding, renal insufficiency and a perceived high bleeding risk. While NOACs significantly reduce the risk of intracranial bleeding as compared to the vitamin $\mathrm{K}$ antagonist warfarin, major bleedings still occur at a rate of $2-3 \%$ per year, despite the fact that important groups of patients were excluded from the phase III NOAC trials based on a perceived high bleeding risk $^{3-5}$. Accordingly, there is a particular important clinical need for stroke prevention in patients with AF who cannot tolerate long-term oral anticoagulation therapy ${ }^{6-8}$. 
In $2016>13,000$ percutaneous LAA occlusions were performed worldwide, illustrating the current need for further advice on the optimised procedural aspects which has been provided in the well-timed consensus statement. However, in contrast to Europe where, due to data from large LAAO registries, several CE-marked devices are used in particular for patients noneligible for long-term $\mathrm{OAC}^{1}$, in 2015, the FDA approved the WATCHMANTM (Boston Scientific, Marlborough, MA, USA) as the only device in the USA as an alternative to OAC, since the only randomised study was performed in patients eligible for warfarin therapy.

The efficacy and safety of LAAO have been analysed in two randomised studies and large-scale prospective observational registries. Additionally, safety will be considerably improved by optimal training of implanters, centre experience and the introduction of improved implantation techniques and LAA occlusion devices. At present, the peri-interventional complication rate is down to less than three percent in experienced centres.

In this issue of EuroIntervention, Glikson et al summarise the scientific background and rationale for the procedure, give a summary and critical appraisal of the available scientific evidence regarding LAAO, define the procedural pitfalls, formulate the requirements for implementation of a structured LAAO programme, characterise indications, and provide an outlook on the currently ongoing controlled randomised clinical studies ${ }^{2}$.

In the present document a careful and systematic review of the new clinical knowledge base on LAA is provided (Figure 1). The 2019 EHRA/EAPCI consensus document update provides numerous recommendations for LAAO. It also acknowledges that further data from randomised clinical trials in different patient populations will provide an important rationale for optimal management in AF patients with a high bleeding risk. Of note, in the field of PFO closure, in 2017 several large-scale randomised trials with longer follow-up provided consistent evidence that the procedure is safe and effective in appropriate patients after TIA or stroke, which has resulted in an increasing clinical adaptation. The ongoing randomised clinical trials on catheter-based LAAO have the potential to have a similar impact on the field of LAAO.

Important takeaway messages and updates since the previous 2014 EHRA/EAPCI consensus document include the following:

- Discussion of CE-certified devices and their implantation techniques with a focus on the WATCHMAN/Amplatzer Amulet device (St. Jude Medical). The LARIAT ${ }^{\circledR}$ device (SentreHEART, Redwood City, CA, USA) is proposed for patients with an absolute contraindication for antithrombotic therapy; however, additional clinical data are needed.

- The important role of multimodal pre-, peri- and post-procedural imaging modalities is highlighted. Coronary computed tomography angiography (CCTA) imaging will become more important in future evaluation and follow-up.

- Recommendations regarding antithrombotic therapy are provided which are based on experience from large registries; but not on randomised clinical trial evidence. Time-limited dual antiplatelet therapy (DAPT) is suggested as the preferred method of post-interventional antithrombotic treatment. Percutaneous LAAO should not be offered to a patient who

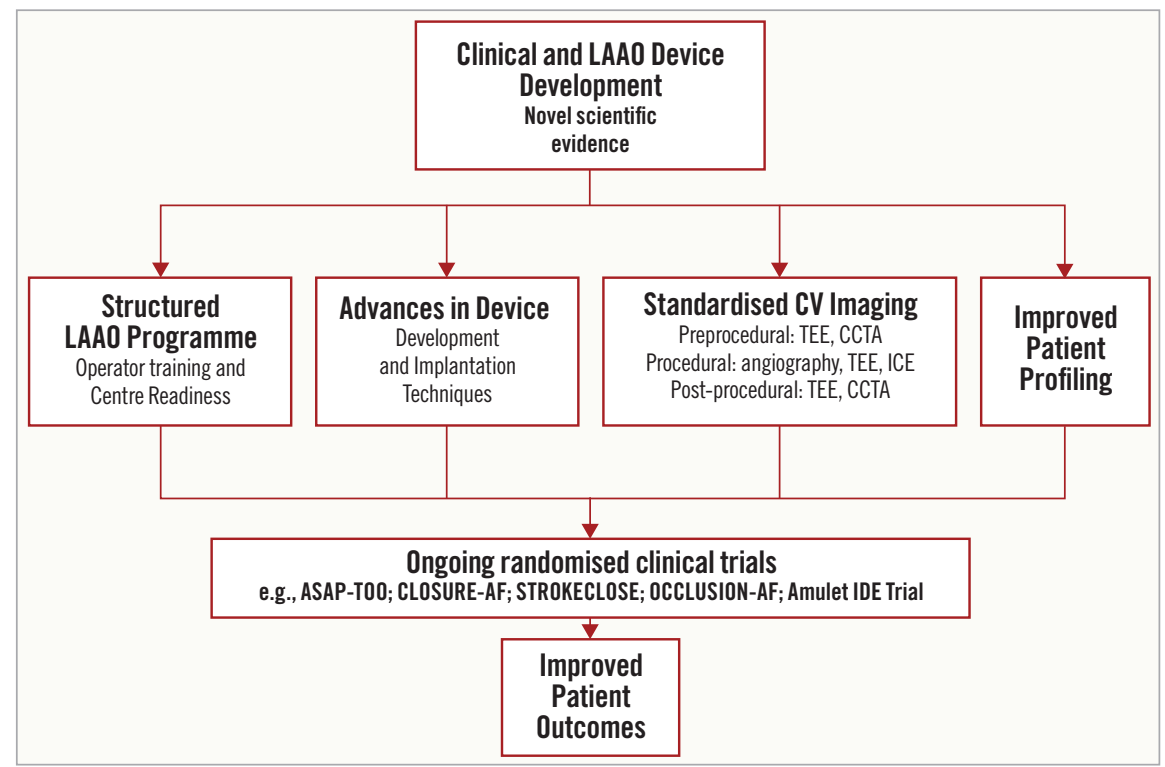

Figure 1. Summary of developments in LAAO reflected in the EHRA/EAPCI expert consensus statement update. The increasing experience in optimising LAAO and future perspectives are summarised. Standards in operator training and centre readiness for a structured LAAO programme are discussed. Device developments and optimal implantation techniques are described. The important role of cardiovascular imaging is highlighted. An outlook on ongoing clinical studies in LAAO that will increase the database is presented. Taken together, the document aims to improve patient outcomes in LAAO. An optimised procedure should be used in clinical practice as well as in ongoing clinical study programmes. 
cannot receive at least several weeks of any antiplatelet therapy. The risk of device-related thrombus formation and the treatment options are discussed.

- Standards for the training of operators and centre readiness are given.

- Ongoing studies and unanswered questions in the field are nicely reviewed.

In summary, LAAO is becoming an increasingly important cardiac procedure and the EHRA/EAPCI consensus statement provides both a scientific update and a large amount of educational information with the aim of further improving the clinical outcomes of LAAO.

\section{Conflict of interest statement}

C. Sturk has received proctoring honoraria from Boston Scientific and Lifetech Scientific. U. Landmesser has received lecture and advisory honoraria from Abbott, Boston Scientific, Biotronik, Bayer and Boehringer.

\section{References}

1. Kirchhof P, Benussi S, Kotecha D, Ahlsson A, Atar D, Casadei B, Castella M, Diener HC, Heidbuchel H, Hendriks J, Hindricks G, Manolis AS, Oldgren J, Popescu BA, Schotten U, Van Putte B, Vardas P; ESC Scientific Document Group. 2016 ESC Guidelines for the management of atrial fibrillation developed in collaboration with EACTS. Eur Heart J. 2016;37:2893-962.

2. Glikson M, Wolff R, Hindricks G, Mandrola J, Camm AJ, Lip GYH, Fauchier L, Betts TR, Lewalter T, Saw J, Tzikas A, Sternik L, Nietlispach F, Berti S, Sievert H, Bertog S, Meier B. EHRA/EAPCI expert consensus statement on catheter-based left atrial appendage occlusion: an update. EuroIntervention. 2020;15:1133-80.
3. Connolly SJ, Ezekowitz MD, Yusuf S, Eikelboom J, Oldgren J, Parekh A, Pogue J, Reilly PA, Themeles E, Varrone J, Wang S, Alings M, Xavier D, Zhu J, Diaz R, Lewis BS, Darius H, Diener HC, Joyner CD, Wallentin L; RE-LY Steering Committee and Investigators. Dabigatran versus warfarin in patients with atrial fibrillation. $N$ Engl J Med. 2009;361:1139-51.

4. Granger CB, Alexander JH, McMurray JJ, Lopes RD, Hylek EM, Hanna M, Al-Khalidi HR, Ansell J, Atar D, Avezum A, Bahit MC, Diaz R, Easton JD, Ezekowitz JA, Flaker G, Garcia D, Geraldes M, Gersh BJ, Golitsyn S, Goto S, Hermosillo AG, Hohnloser SH, Horowitz J, Mohan P, Jansky P, Lewis BS, Lopez-Sendon JL, Pais P, Parkhomenko A, Verheugt FW, Zhu J, Wallentin L; ARISTOTLE Committees and Investigators. Apixaban versus warfarin in patients with atrial fibrillation. $N$ Engl J Med. 2011;365:981-92.

5. Patel MR, Mahaffey KW, Garg J, Pan G, Singer DE, Hacke W, Breithardt G, Halperin JL, Hankey GJ, Piccini JP, Becker RC, Nessel CC, Paolini JF, Berkowitz SD, Fox KA, Califf RM; ROCKET AF Investigators. Rivaroxaban versus warfarin in nonvalvular atrial fibrillation. $N$ Engl J Med. 2011;365:883-91.

6. Kirchhof P, Ammentorp B, Darius H, De Caterina R, Le Heuzey JY, Schilling RJ, Schmitt J, Zamorano JL. Management of atrial fibrillation in seven European countries after the publication of the 2010 ESC Guidelines on atrial fibrillation: primary results of the PREvention oF thromboemolic events-European Registry in Atrial Fibrillation (PREFER in AF). Europace. 2014;16: 6-14.

7. Lip GY, Laroche C, Ioachim PM, Rasmussen LH, Vitali-Serdoz L, Petrescu L, Darabantiu D, Crijns HJ, Kirchhof P, Vardas P, Tavazzi L, Maggioni AP, Boriani G. Prognosis and treatment of atrial fibrillation patients by European cardiologists: one year follow-up of the EURObservational Research Programme-Atrial Fibrillation General Registry Pilot Phase (EORP-AF Pilot registry). Eur Heart J. 2014;35:3365-76.

8. Bassand JP, Accetta G, Camm AJ, Cools F, Fitzmaurice DA, Fox KA, Goldhaber SZ, Goto S, Haas S, Hacke W, Kayani G, Mantovani LG, Misselwitz F, Ten Cate H, Turpie AG, Verheugt FW, Kakkar AK; GARFIELD-AF Investigators. Two-year outcomes of patients with newly diagnosed atrial fibrillation: results from GARFIELD-AF. Eur Heart J. 2016;37:2882-9. 